\title{
Culture and Social Relationship as Factors of Affecting Communicative Non-verbal Behaviors
}

\author{
Afia Akhter Lipi Dept. of Computer and Information Science, Seikei University \\ afiaakhter@hotmail.com, http://www.seikei.ac.jp/index-e.html \\ Yukiko Nakano Dept. of Computer and Information Science, Seikei University \\ y.nakano@st.seikei.ac.jp, http://www.seikei.ac.jp/index-e.html \\ Mathias Rehm \\ Dept. of Media Technology, Aalborg University, Denmark \\ matthias@imi.aau.dk, http://www.imi.aau.dk/
}

Keywords: social and cultural characteristics, posture, socio-cultural model

Summary: The goal of this paper is to link a bridge between social relationship and cultural variation to predict conversants' non-verbal behaviors. This idea serves as a basis of establishing a parameter based socio-cultural model, which determines non-verbal expressive parameters that specify the shapes of agent's nonverbal behaviors in HAI. As the first step, a comparative corpus analysis is done for two cultures in two specific social relationships. Next, by integrating the cultural and social parameters factors with the empirical data from corpus analysis, we establish a model that predicts posture. The predictions from our model successfully demonstrate that both cultural background and social relationship moderate communicative non-verbal behaviors.

\section{Introduction}

Although we live in a globalized world, local or cultural identities strongly influence the patterns of our conversational behavior and our interpretation of such behavior by others through the establishment of norms and values. Nevertheless; current conversational interfaces seldom take into account such cultural "mental programs," as Hofstede [Hofstede 2001] has termed this effect. In general communication, people are forced to adapt their mode of interaction and interpretation to a given (and most of the time Western) perspective. It would be much more reasonable, however, to account for these differences in the design of the interfaces, and to do so, it would be necessary to enculturate these interfaces. Therefore, as emphasized above, an understanding of the cultural background is crucial for designing user interfaces that people can accept and use; however, only a few studies have focused on this point.

There are many examples that demonstrate how communicative behavior is exhibited differently in different cultures based on different social relationships. For instance, in the American culture, looking directly into the eyes of a person to whom one is speaking is seen as a positive trait, while in the Japanese culture, looking too directly at someone is considered negative, rude, and improper [Dusan 2007]. In South Korea and Japan, rigid postures are considered indicative of influential persons while in America, relaxed postures give an impression of credibility [Badler \& Allbeck 2004].

Literature provides considerable evidence that communicative behavior is affected by differences in cultural and social relationships. Unfortunately, these results are not statistical or specific enough to establish a quantitative model. In this study, therefore, we focus on analyzing and comparing the non-verbal behavior of different cultures in different social relationships in a quantitative manner.

As a first step, using the CUBE-G corpus [Rehm \& Nakano 2009] we conduct a comparative corpus analysis of two different cultures, the German and Japanese, as reflected in two different social relationships: first-time interactions and interaction with someone of higher social status. In the corpus analysis, we employ Hofstede's theory [Hofstede 2001] on cultural factors, and we propose factors for social relationship that are based on studies of social psychology. We then investigate how these factors affect the postures of the people in conversation.

Finally, after integrating the empirical data 
extracted from our corpus analysis with selected cultural and social factors, we propose a socio-cultural model that can predict modes of nonverbal expression, specifically parameters for postural expressivities.

The structure of this paper is as follows. In Section 2 , we discuss relevant work in the area of communicative behavior, as a product of culture and social relationships. In Section 3, we introduce the theoretical terms used in this study. In Section 4, we report upon the results of our corpus analysis. Based on the results, Section 5 proposes a socio-cultural model that links culture and social relationships with empirical data to predict postural expressivity. Finally, in Section 6, we offer conclusions and describe areas of future work.

\section{Related Work}

Study of the literature reveals how culture and social relationships affect human communicative behavior.

\subsection{Culture and human communicative behaviors}

According to [Sanchez 2009], cultural differences determine how individuals experience and perform in workplace interactions. They studied how culture-based differences in relational attunement affect Anglos and Latinos in the U.S. differently. With a focus on behavioral mirroring, they discovered stronger effects of behavioral mirroring among Latinos than among Anglos. This result suggests that ethnicity and culture, and not demographic variables, are the key factors and predictors of differences in cognitive styles.

[Dusan 2007] presented a model for simulating culturally specific behavior for Anglo American, Mexican Spanish, and Arab people with respect to proxemics, gaze, and overlap in turn-taking. However, there was insufficient quantitative data on gaze and overlap in turn-taking and a lack of literature on these subjects for Arab culture. Thus, they made approximations on the basis of available qualitative descriptions.

In a study of the building of culturally adaptive agents, O'Neill-Brown [1997] discussed how culture and communicative behavior are interwoven, one helping to shape the other. She asserted that culture helps to define rules and patterns of behaviors, shapes users' modes of interaction and communication, and influences individual character and styles of communication. The verbal and non-verbal behaviors that individuals display in conversation are a product of their culture. For example, when an American native speaker of English asks a question "Who, me?", he/she points to himself/herself, usually to the upper chest. When a Japanese asks the same question, he/she points to his/her nose. Thus, individual communicative behavior can indicate where a person is from or which group he/she belongs to.

[Samuel et al. 2009] also emphasized the cultural aspects, while developing the idea of embodied agents. Taking Hofstede's dimensions of culture [Hofstede 2001] as a baseline, they also modeled culture in an agent's architecture with the hope of building a natural form of interaction with agents. They explored the concept of factor-goal utility, which regards what an agent will do at any given moment, and emotional appraisal, which simulates emotional responses to events. As a result, they discovered the importance of culture in the enhancement of the social dynamics of agents.

\subsection{Social relationship and human communicative behaviors}

In addition to cultural aspects, socio-linguistics research has focused on the social roles and social relationships involved in the use of language and nonverbal behavior. In their study of communicative behavior and culture, analyzed language within the framework of social activities, and they discovered that specific patterns and social rules are set as the context in which conversation is conducted. In [Robert et al. 1985], it was shown that, depending on the circumstances and the relationship between people, a speaker could perform the act of asking another person to close a door by saying, "Shut the door," or "Would you mind closing the door?" As another example, a college professor named Mary Smith might be called "Professor Smith," "Ms. Smith," "Mary," "ma'am," etc., with each form reflecting a different conception of the relationship between the speaker and addressee.

[Dana et al. 2005] gave an account of how non-verbal behaviors are associated with different degrees of perceived social power. In their study, they examined different types of non-verbal behaviors such as postures, gestures, head movements, gaze, and proxemics among many others. They found significant and interesting results for each category of 
non-verbal behavior. With postural behaviors, for example, they found that individuals with greater power are believed to have a more erect posture, lean forward more, present an open body position, and orient their body toward the other person. Within the category of head movement, these same individuals were expected to engage in more upward tilting of the head, orienting of head toward the other person, and shaking of the head.

\subsection{Interaction between culture and social relationship in human communicative behaviors}

A cross-cultural study was carried out by Triandis et al. [Triandis \& Harry C. 1989], in which they investigated how different behaviors are associated with different social roles. They asked American and Greek subjects to judge the appropriateness of certain behaviors for given role relationships. Analyzing the factors in their results, they found four factors that were common to the two cultures when people form judgments about social interaction with others: affect, intimacy, dominance, and hostility

\section{Theoretical Foundation}

This section describes the theoretical terms used in this study.

\subsection{Parameters characterizing posture}

Posture is defined as a motion or position shift of the human body [Cassell et al. 2001]. Literatures shown in Section 2 provided enough data that, postures are exhibited differently depending on the culture and social relationship. However, not much numerical data were there which can be used in establishing a parameter-based model. Thus, this research conducts an empirical study of posture in different cultures and different social relationships.

To define parameters that characterize postures, we reviewed previous studies. To describe cultural differences in gestures, [Efron 1972] proposed parameters such as spatio-temporal aspects, interlocution aspects, and co-verbal aspects. Using a factor analysis, [Gallahar 1992] revealed four dimensions; expressiveness, expansiveness, coordination, and animation. Based on these previous studies, [Hartmann et al. 2005] defined gestural expressivity using six parameters: repetition, activation, spatial extent, speed, strength, and fluidity.

Finally, based on the literature study above, we came up with four parameters, which define the characteristics of postures. The four parameters are duration, spatial extent, rigidness and mirroring as shown in Table1.

Table1: Definition of posture characteristics

\begin{tabular}{|c|c|}
\hline \begin{tabular}{|l|} 
Posture \\
Characteristics
\end{tabular} & Definition \\
\hline Duration & $\begin{array}{l}\text { Duration till which a person remains in the } \\
\text { same posture }\end{array}$ \\
\hline Spatial Extent & Amount of space used in a posture \\
\hline Rigidness & $\begin{array}{l}\text { Rigidness or relaxation apparent from the } \\
\text { posture }\end{array}$ \\
\hline Mirroring & $\begin{array}{l}\text { Number of instances when an individual } \\
\text { unconsciously imitates a partner's posture } \\
\text { during a conversation }\end{array}$ \\
\hline
\end{tabular}

\subsection{Parameters characterizing culture}

From a theoretical approach, we employ Hofstede theory [Hofstede 2001] to describe cultural characteristics. The reason of taking Hofstede theory is, Hofstede defines culture using five dimensions and they are quantitative in nature. Each dimension is described below.

1. Hierarchy (Small/Large): Hierarchy is the extent to which the members of society accept unequal distribution of power. This affects the behavior of both less powerful and more powerful members. The fundamental issue addressed by this dimension is how a society handles inequalities among people. This has consequences for building institutions and organizations.

2. Identity (Individualism/Collectivism): This is the degree to which individuals are integrated into a group. On the individualist side, ties between individuals are loose, and everybody is expected to take care for herself/himself. On the collectivist side, people are integrated into strong and cohesive groups. 3. Gender (Masculinity/Femininity): The gender dimension describes the distribution of roles between the genders. In feminine cultures the roles differ less than in masculine cultures, where competition is rather accepted and status symbols are of importance.

4. Uncertainty Avoidance (Weak/strong): The tolerance for uncertainty and ambiguity is defined in this dimension. It indicates to what extent the members of a culture feel either uncomfortable or comfortable in unstructured situations, which are 
novel, unknown, surprising, or different from usual.

5. Orientation (short/Long): This dimension distinguishes long and short-term orientation. Short term orientation stands for a society fostering virtues oriented towards persistence and perseverance, thrift, ordering relationships by status and observing this order by having a sense of shame. Long term orientation stands for a society fostering virtues of personal steadiness and stability, protecting face, respect for tradition and reciprocation of greetings, favors and gifts.

Since cultural characteristics in Hofstede theory are synthetic, a set of parameter values indicates the cultural profile. Table 2 gives Hofstede's ratings for three countries. For example, in Identity dimension, Germany (67) is more individual culture than Japan (46), and US (91) is the most individual among three.

Table 2: Hofstede ratings for three countries

\begin{tabular}{|c|c|c|c|c|c|}
\hline & Hierarchy & Identity & Gender & Uncertainty & Orientation \\
\hline Germany & 35 & 67 & 66 & 65 & 31 \\
\hline Japan & 54 & 46 & 95 & 92 & 80 \\
\hline US & 40 & 91 & 62 & 46 & 29 \\
\hline
\end{tabular}

\subsection{Parameters characterizing social relationship}

In our study, social relationship is another predictor of non-verbal behaviors. There is no proper terminology to define social relationship, and different researchers in cross-cultural pragmatics conceptualize it differently. Thus, we review many social psychological studies, and found six parameters are there which explain social relationship. As the concepts of two parameters are overlapped so finally we selected four parameters from [Spencer-Oatey 1996]: power, sense of like-mindedness, frequency of contact, and length of relation. Each parameter is described below.

1. Power $(H i g h / L o w):$ This parameter indicates the power of the speaker over the hearer in a given role relationship. One person is said to have the power over another in the degree that he is able to control the behavior of the other. There are many bases of power such as physical strength, wealth, age, institutionalized role [Spencer -Oatey 1996]

2. Sense of like mindedness (High/Low). This concept refers to the situation where, two individuals share similar views or opinion which lead to a strong relationship between them [Spencer -Oatey 1996].

3. Frequency of contact (High/Low): It is another social dimension, which determines relationship. Frequent of contact relates to distance/intimacy. More frequent contact does not always mean intimacy or are not always associated with positive affect. For instance, colleagues who have worked together for many years may be rivals and dislike each other [Spencer -Oatey 1996].

4. Length of relation (Long/Short): This social attribute also measures role relationship. The duration of relation affects the degree of closeness in a personal relationship [Spencer-Oatey 1996]. In cross-cultural research, people from different cultures view each of these aspects in a different way. For example, friends are treated as close by Lim and Bowers but as an intermediate in terms of closeness/distance by Blum-Kulka [Spencer-Oatey 1996].

\section{Extracting empirical data from comparative corpus analysis}

This section reports the results of a comparative corpus analysis of an international German-Japanese CUBE-G project [Rehm \& Nakano 2009]. To gather information about cultural heuristics in face-to-face interactions, three prototypical dyadic interaction scenarios were defined that are found in every culture: a first-time encounter, a negotiation process, and the interaction of individuals of different social status. A total of twenty one subjects (11 male, 10 female) participated in the collection of data on Germans, and twenty six subjects (13 male, 13 female) for the corresponding data on the Japanese. For each subject, approximately 25 minutes of video material was collected; 5 minutes for the first meeting, 10-15 minutes for the negotiation, and 5 minutes for the encounter between people of different social status.

As a next step, we annotated the verbal and non-verbal behavior patterns found in the two cultures for the three scenarios, using the tool ANVIL [Kipp, M. 2001]. The behaviors that were annotated are postures [Bull 1987], gestural expressivity [Pelachaud 2005], eye gaze, and transcription of speech. Details of the CUBE-G corpus collections and annotations are provided in [Rehm \& Nakano 2009]. 
In this study, we concentrated mainly on analyzing the data on posture for forty minutes (=8 conversations of 5 minutes each) video data for German and fifty minutes (=10 conversations of 5 minutes each) video data for Japanese first time encounter and forty minutes $(=8$ conversations of 5 minutes each) video data for German and forty minutes (=8 video data of 5 minutes each) video data for Japanese, interactions with higher status person. Four students were involved in annotating the Japanese postures, and two students annotated the German postures. The annotators, who were from both countries, used the same coding scheme that specified how to label each type of head, leg and arm posture [Bull 1987]. For the head, there were a total of six categories, for the leg, six categories, and for the arms, sixteen categories. These were derived from Bull's coding scheme [Bull 1987], which enabled us to analyze postures with respect to culture and social relationship.

\subsection{Analysis with respect to culture}

This section describes how differences between the Japanese and German cultures affect the four parameters of posture defined in Table 1. Further details of how each of the posture characteristics varied with respect to culture are given in [Lipi 2009].

\subsubsection{Results}

\section{Duration:}

Table 3 shows that Japanese people stay in one posture longer than German people. German people, however, hold their legs in the same posture for a longer duration than Japanese.

Table 3: Duration of posture shifts (sec)

\begin{tabular}{|c|c|c|c|}
\hline Culture & Head & Arm & Leg \\
\hline Japanese & 2.54 & 12.00 & 15.39 \\
\hline German & 2.18 & 7.79 & 20.00 \\
\hline
\end{tabular}

Spatial Extent and Rigidness: The posture shape indicate whether it is big or small, relax or rigid. In our nonverbal data analysis, we found that, arm posture shapes frequently observed in Japanese culture are JHs (join hands), PHFe (put hand on face) and PHB (put hand back). In German culture, the frequently observed posture shapers are PHIPt (Put hands in pocket), FAs (Folded arms) and PHEw (Put hands on elbow) when interacting with someone for the first time.

Next, we conducted an experiment in which we asked subjects to rate the scores of spatial extent and rigidity on a 7 point scale [Lipi 2009]. The results are shown in Figs. 1 and 2. As shown in the figures, ratings for postures frequently observed in German corpus, such as PHIPt and FAs, were higher in spatial extent and lower in rigidness compared to postures frequently observed in Japanese data, such as JHs and PHB. The average spatial extent score for the Germans is 4.04 and for the Japanese is 1.97, and the average rigidity score for the German is 5.56 and for the Japanese is 2.38. These results suggest that Germans assume more expansive and more relaxed postures than the Japanese.

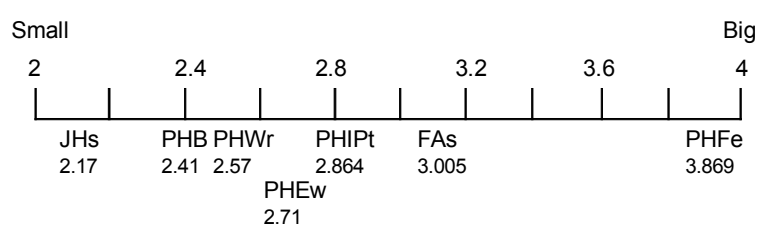

Fig. 1: Ratings of spatial extent for frequently observed postures

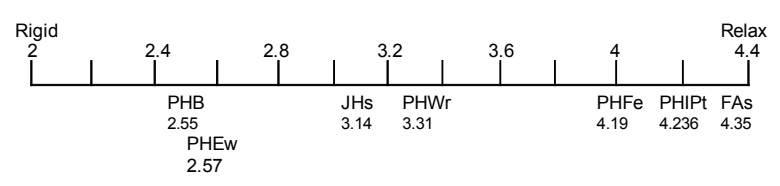

Fig. 2: Ratings of rigidity for frequently observed postures

Mirroring: The average number of mirroring events for Japanese arm and leg postures is 5.5 and 1.11 respectively, while for German culture, the result for arm posture is 0.857 , and no mirroring occurred in shifts of leg posture. These results suggest that members of the collectivistic culture of the Japanese [Sanchez 2009] are more likely to move in synchronicity with their conversation partner than members of the individualistic culture of the Germans.

\subsubsection{Discussions}

Table 4: Posture characteristics with respect to cultures

\begin{tabular}{|c|c|c|c|c|}
\hline Culture & Duration (sec) & $\begin{array}{c}\text { Mirroring } \\
\text { (times/dialogue) }\end{array}$ & $\begin{array}{c}\text { Spatial Extent } \\
\text { (point) }\end{array}$ & $\begin{array}{c}\text { Relax } \\
\text { (point) }\end{array}$ \\
\hline Japanese & 12.26 & 5.50 & 1.97 & 2.38 \\
\hline German & 7.79 & 0.88 & 4.04 & 5.56 \\
\hline
\end{tabular}

Since we found such a clear cultural difference in shifts in arm posture, we then focused on measuring the results for this posture. Table 4 presents all the 
posture parameter values for arm posture. The results show that the Japanese stay in the same posture longer, engage in more frequent mirroring, take up less space, and display a more rigid posture in comparison to Germans. We can thus see that non-verbal parameters are affected by cultural differences.

\subsection{Analysis based on Social Relationship}

We analyze postures in two different social relationships in CUBE-G corpus; interacting with someone for the first time and interacting with someone of higher status, and investigate the four posture characteristics defined in Table 1.

\subsubsection{Results}

Duration: Table 5 shows that both groups hold the same arm and leg postures for a longer duration, but the duration of head postures is shorter during interaction with people of a higher social status than it is during first-time interactions

Table 5: Duration in Two Social Relationships

\begin{tabular}{|c|c|c|c|c|}
\hline Culture & Social Relationship & Head & Arm & Leg \\
\hline \multirow{2}{*}{ Japanese } & First Time & 2.54 & 12.26 & 15.39 \\
\cline { 2 - 5 } & Higher Status & 2.40 & 43.52 & 66.13 \\
\hline \multirow{2}{*}{ German } & First Time & 2.18 & 7.79 & 20.09 \\
\cline { 2 - 5 } & Higher Status & 1.73 & 20.43 & 36.17 \\
\hline
\end{tabular}

Spatial Extent and Rigidness: When interacting with higher status person, the frequently observed posture shapes in Japanese culture are JHs(join hands), PHFe(put hand on face) and PHB (put hands back), and in German culture are $\mathrm{JHs}$ (join hands), PHIPt (put hands in pocket), FAs(folded arms). Interestingly, German posture shapes like Japanese posture shapes are distributed more to the left side in the spatial Extent and Rigidity rating scale given in Fig. 1 and Fig. 2. This indicates that both Japanese and German make smaller postures, and the postures are more rigid when interacting with higher status persons than interacting with someone for the first time.

Mirroring: During first-time interactions, the average number of mirroring events per conversation is 6.2 for the Japanese and 0.57 for Germans. On the other hand, in both cultures there was no mirroring during interaction with persons of higher status, and persons of higher status remained in rigid leg postures throughout the dyadic conversations.

\subsubsection{Discussions}

Table 6 summarizes all the results for arm posture.
In both the German and Japanese cultures, the duration is longer, no mirroring occurs, and the posture is more rigid and contracted during interaction with a person of higher social status than it is during first-time interactions. The Proportion (FT/HS) in the fourth and seventh rows of Table 6 shows the proportions of First Time (FS) to Higher Status (HS) for each variable. Note that the results for the two cultures are quite close to one another. For instance, FT/HS for duration is 0.28 for the Japanese and 038 for the Germans. This suggests that social relationships have a uniform effect on non-verbal parameters in both cultures.

Table 6: Posture Characteristics with respect to Social Relationships

\begin{tabular}{|c|c|c|c|c|c|c|}
\hline Culture & Social Relationship & Frequency & Duration & Mirroring & Spatial extent & Relax \\
\hline \multirow{4}{*}{ Japanese } & FirstTime(FI) & 4.60 & 12.26 & 5.50 & 1.97 & 2.38 \\
\cline { 2 - 7 } & Highher Status(HS) & 1.32 & 43.52 & 0.00 & 0.54 & 0.725 \\
\cline { 2 - 7 } & Propotion(FT//HS) & 3.48 & 0.28 & 0.00 & 3.63 & 3.29 \\
\hline \multirow{4}{*}{ Germann } & Firsttime & 8.075 & 7.79 & 0.875 & 4.04 & 5.56 \\
\cline { 2 - 7 } & Higher status & 2.375 & 20.43 & 0.00 & 0.98 & 1.44 \\
\cline { 2 - 7 } & Proportion(FT/HS) & 3.40 & 0.38 & 0.00 & 4.10 & 3.85 \\
\hline
\end{tabular}

Thus, our results prove that social relationships also affect the parameters of non-verbal behavior. As a consequence, it seems quite clear that social aspects must be taken into account as well as cultural aspects.

\subsubsection{Relationship between cultural factors and social factors}

Our corpus analyses suggest that both cultural differences and social relationships affect the characteristics of postures. The question then arises as to how these two factors should be linked together to determine non-verbal behaviors. Culture influences how different people interpret and evaluate their social interactions [Sanchez 2009]. For instance, the bowing ritual in Japan is a well-known example of a culture-specific non-verbal way of conveying status [Isbister 2004]. As another example, in Japan, a rigid posture indicates an influential person, while in the U.S., a relaxed posture gives an impression of credibility [Badler \& Allbeck 2004]. In addition, psychological research indicates that attitudes toward power are different in different cultures. In the West, the term power is closely associated with domination and control and is viewed 
negatively, while in China and Japan, the vertical power relationship is seen positively; the superior member does not simply dominate or control the other, as both members are bound together in a relationship that involves considerable mutual responsibility [Spencer 1996]. Thus, cultures vary in their attitude toward social relationships.

\section{Linking a bridge between social and cultural factors to predict nonverbal behaviors}

This section describes how socio-cultural factors are integrated into a network model to predict non-verbal behaviors in different cultures and different social relationships.

When designing a network model, many issues must be addressed. What should be the structure of the network? Which factors should have priority? Do the culture and social factors determine the non-verbal norms, or do the non-verbal norms represent socio-cultural characteristics?

To address such questions, we employed a Bayesian network to represent a socio-cultural model of posture characteristics. The model could be used to select or modify the nonverbal behaviors of conversational agents by setting the evidence for a given culture and social relationship. The model could also infer the cultural background and the social situation from the given nonverbal behavioral characteristics. Another reason for using a Bayesian network is its strength in dealing with incomplete and unreliable knowledge and its capacity to handle uncertainty at every stage.

\subsection{The structure of the network}

In order to build a Bayesian network, the GeNie [GeNIe, 1998] modeling environment was used. Fig. 3 shows our Bayesian network model, which integrates social and cultural factors. To design the structure of the network, that is, the linkage of the parent node to the child node, we carefully scrutinized the empirical data obtained from our corpus analysis and from previous findings and studies. Next, we present a more detailed discussion of the network design.

\section{Top layer}

The entry nodes of the Bayesian network are a culture relationship node and a social relationship node. Currently, we have implemented two cultures, the German and Japanese, and two social relationships, first-time interactions and interactions with a person of higher social status.

\section{Cultural parameters}

For the cultural factor layer, we employed Hofstede's five dimensions, which were described in Section 3.2, integrating all five dimensions: hierarchy, identity,

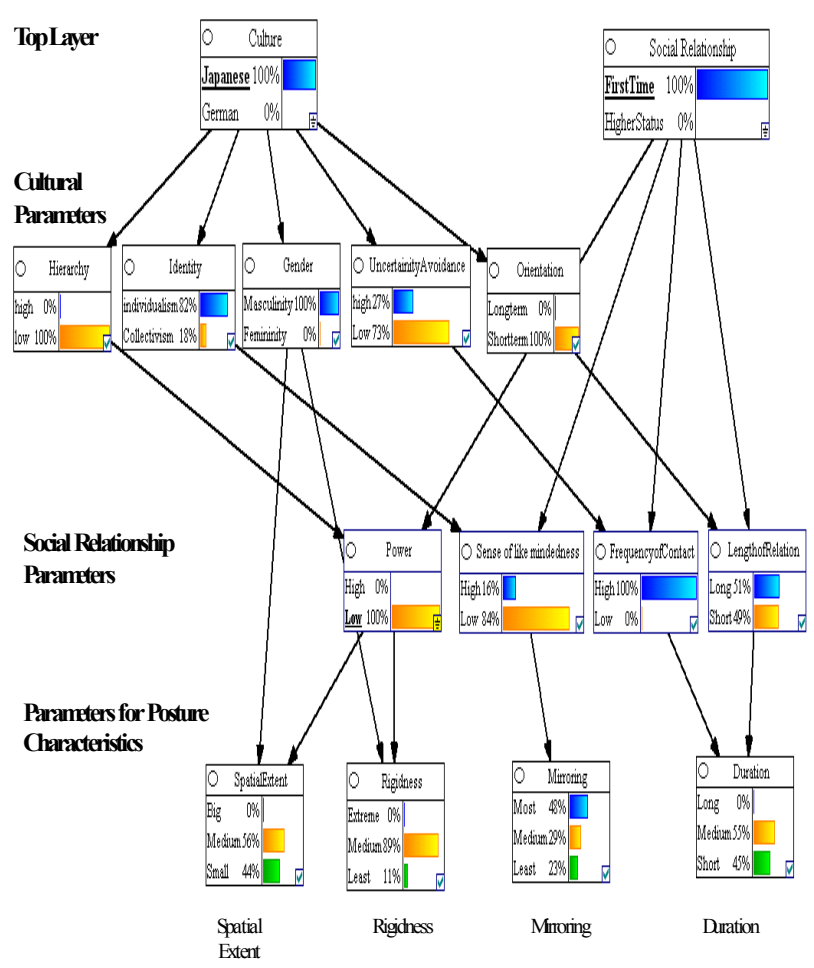

Fig. 3: A Bayesian network model connecting cultural and social factors with non-verbal behaviors

gender, uncertainty avoidance, and orientation. Hofstede's ratings for each culture, which are shown in Table 2, are used as the probabilities in each node for each culture. For example, as shown in Table 2, the value for probabilities for the node "Hierarchy" is 0.35 for German and 0.54 for Japanese culture.

\section{Social relationship parameters}

For the social relationship parameters, we employed those proposed in [Spencer-Oatey 1996], which were explained in Section 3.3. Unlike the case of cultural parameters, we did not know the parameter settings to represent each culture type: first-time interactions and interactions with a person of higher status. We therefore employed an EM algorithm to estimate the probability for each cultural parameter, using the other nodes as evidence.

Next, we designed the linkage between the cultural 
parameters and the social relationship parameters. Since culture influences people's behaviors in different social roles and relationships [Samuel 2009a], we employed Hofsted's cultural parameters as the parent nodes to the social relationship nodes. In addition, as reported in Sections 4.2.2 and 4.2.3, we found that the cultural factor has a uniform effect upon social relationships. We therefore connected these two factors in a straightforward way without considering the interaction between them. The links for each node are described as follows.

Power: We linked Hofstede's dimension of "Hierarchy" with that of "Power" as a social relationship parameter. We found that a person's status or social rank may be constructed both absolutely in a stable social hierarchy and in relation to another member with whom he is currently interacting [Spencer-Oatey 1996]. Sense of like-mindedness: People whose minds are similarly attuned usually share a similar vision or similar ideas. According to Hofstede's theory, Japanese culture is a collectivistic society. The Japanese are therefore more harmonious than the Germans, who belong to an individualistic society. "Identity" represents the degree to which people are integrated into a group. We therefore linked "Identity" with the sense of like-mindedness as it relates to people's self-concept of "I" or "We."

Frequency of contact, Length of relation: We linked frequency of contact and length of relation with "Uncertainty avoidance" and "Orientation", as these parameters all represent linearity of time. In Japanese society, which is characterized by high uncertainty avoidance, there is a more rigid code of conduct, and a higher frequency of contact in business and social-level interaction. Also, since the Japanese culture has a long-term orientation, they believe in long-term relationships in business. Personal steadiness and stability, respect for tradition, and reciprocation of greetings are important in Japanese society.

\section{Parameters for posture characteristics}

The lowest layer consists of parameters of the posture characteristics described in Section 3.1. The parameters of this layer depend on the culture's position in terms of Hofstede's dimensions as well as the social relationship. For each node, we created three gradations or states to denote high, low, and medium. For instance, for spatial extent, we used the three states of small, medium, and big. We likewise created three states for the parameters of mirroring, duration, and rigidity.

Spatial Extent: From our experimental data, we found that Germans assume larger postures than the Japanese. When we compared the postures of male and female subjects, we found that Japanese females assume smaller postures than the males, and that the difference between the posture sizes of the two sexes is greater than it is among Germans. In addition, at a higher status or social rank, people seem to assume smaller postures [Ting-Toomey, S. 1999]. [Badler \& Allbeck 2004] studied the interactions between individuals of high and low social status, and reported that non-verbal behaviors are strongly affected by the differences in social power. These claims suggest that both "Power" and "Gender" influence the "Spatial Extent". In our empirical data, we found that gender has an effect upon both spatial extent and rigidity. Female subjects assume smaller and more rigid postures than male subjects. Based on the above discussion, we made a connection between "Power" and "Gender", and "Spatial extent".

Rigidity: Our experimental data revealed that the Japanese assume more rigid postures than Germans. Badler \& Allbeck [2004] reported that during interaction with persons of higher social status, individuals were believed to assume more erect postures. In addition, we found from our corpus analysis that females assume more rigid postures than males. We therefore assume a linkage between "Power" and "Gender", and "Rigidity".

Mirroring: Sanchez [2009] has argued that people often monitor their social environment at an unconscious level, looking for cues that tell them the degree to which other people like and accept them. They found that participants who mirrored each other's behavior perceived themselves as more likable and considered their interactions smoother than did those who did not mirror each other's behavior. We therefore assumed a linkage between "Sense of like-mindedness" and "Mirroring".

Duration: We linked the parameter of "Frequency of relation contact" and "Length of relation" to that of "Duration" of posture because they all represent linearity of time.

Given the network structure shown in Fig.3, we used an EM (Estimation-Maximization) algorithm to estimate the probabilities for four social relationship parameters based on the values for Hofstede's five dimensions (cultural parameters) and those for 
posture characteristics obtained from the empirical study. Since we analyzed 34 conversations in our empirical study, which is discussed in Section 4, all the empirical data were used for the parameter learning.

\subsection{Preliminary evaluation}

As a preliminary evaluation, we tested our model by specifying the culture type and the social relationship type on the top level as evidence, and showed that the predicted posture characteristics could successfully determine the different combinations of culture and social relationship types.

First, as shown in Fig. 3, when Japan is chosen as the evidence for Culture and First time Meeting as the evidence for Social Relationship, the results of estimation are; spatial extent is medium (56\%), rigidness is medium (89\%), mirroring is most (48\%) and duration is medium (55\%). Then keeping Japan as the evidence for culture and selecting Higher Status as the evidence for Social Relationship, the estimation results are; spatial extent is small(89\%), rigidness is extreme (78\%), mirroring is least (100\%), and duration is long (89\%).

Next, selecting German as evidence for culture and First time Meeting as the evidence for Social Relationship, the results are; spatial extent is big $(57 \%)$, rigidness is least $(71 \%)$, mirroring is least (85\%) and duration is short (86\%). Then keeping German as evidence for culture and changing Higher Status as the evidence for Social Relationship, the results are; spatial extent is medium (62\%), rigidness is medium (88\%), mirroring is least (100\%) and duration is medium (38\%).

As described above, the network predicts a smaller spatial extent, more rigidity, more frequent mirroring, and postures of longer duration for Japanese culture as compared to German culture. The network also predicts a smaller spatial extent, more rigidity, no mirroring, and a longer duration for communication with people of Higher Status as compared to First-time Interactions. These results are the same as those found in our empirical study, which is discussed in Section 4.

More intriguingly, except for mirroring, the network outputs a very similar prediction for Japanese first-time interactions and German communication with people of higher status: the spatial extent, rigidity, and duration of posture are all medium. The similarity of these two cases was also found in our empirical study shown in Table 7.

Table 7: Posture distribution in German and Japanese data

\begin{tabular}{|c|c|c|c|c|c|}
\hline Culture & $\begin{array}{c}\text { Social } \\
\text { Relationship }\end{array}$ & \multicolumn{4}{|c|}{ Posture Distribution } \\
\hline \multirow{2}{*}{ Japan } & FirstTime & JHS29.56\% & PHFe $20.86^{\circ} /$ & PHB 14.78\% & PHWr 12.17\% \\
\hline & HigherStatus & JHS56.06\% & PHB $19.69^{\circ} /$ & PHFe $10.60^{\circ}$ & PHWr 7.57\% \\
\hline \multirow{2}{*}{ German } & FirstTime & PHIpt $40.55 \%$ & FAs $18.88 \%$ & PHEw $13.93 \%$ & PHB $6.80 \%$ \\
\hline & HigherStatus & $\mathrm{JHs} 36.81 \%$ & PHIpt 23.15\% & PHFe 6.31\% & PHB $6.31 \%$ \\
\hline
\end{tabular}

Table 7 shows the percentages of frequently observed postures. In Japanese first-time meeting, the most frequent posture is JHS, the next frequent is PHFe, and then PHB. Note that JHS is the most frequent in German higher status, too. Then, PHFe is the third, and the PHB is the fourth in German higher status. This suggests that these two cases have similar posture shapes distributions.

These results indicate that the posture characteristics predicted by the model are fully supported by our corpus.

\section{Conclusion and Future work}

This research sheds light on how non-verbal behaviors are moderated by culture and social relationship. Our study has found satisfactory evidence that these two factors are useful predictors of behavioral styles. Focusing on two cultures, we extracted statistical data for non-verbal behaviors in two different social relationships. We then integrated these data with cultural and social factors to set up a Bayesian network that generated non-verbal behavioral parameters. We also showed that our model performed well at distinguishing different combinations of culture and social relationship types.

We admit that global and quantitative evaluation is necessary, but it is almost impossible to collect fully comparative corpus like our CUBE-G corpus in various cultures and social relationship types. An alternative is to measure the model's prediction accuracy by rating the naturalness of the posture performed by an animated character. A number of different scenarios with variation of postures will be created with respect to different culture and social status. Then, ask each subject to rate the videos with respect to their naturalness. This method enables to examine the performance for other cultures, for which 
we do not have corpus data, and is expected to be a comprehensive account of posture formulation. In addition to evaluating the performance of the proposed model, through these experiments, we will discuss whether the structure of our Bayesian network model is suitable for and applicable to various cultures and social relationships, and will modify the network structure if necessary.

As a future direction, we will employ this model in a distance-learning system on the web in which two users from different countries can log on to the service and teach their respective languages to one another. In such an application, the system would not only help the user to learn a language, but also familiarize the learner with other culture-specific nonverbal behaviors. This research is therefore a preliminary step in the development of a virtual learning scenario that allows users to experience culturally determined differences in communicative behavior. The implementation of the posture prediction mechanism in this distance learning system is currently in progress. The final evaluation of the proposed model will seek to determine its effectiveness and usefulness in such practical applications.

Acknowledgment: The work described in this paper was partially supported by the German Research Foundation (DFG) with research grant RE2619/2-1, the Japan Society for the Promotion of Science (JSPS) with a grant-in-aid for scientific research (C) (19500104), and by the European Community (EC) in the eCIRCUS project IST-4-027656-STP.

\section{$\diamond$ References $\diamond$}

[Badler \& Allbeck 2004] Badler \& Allbeck: Creating Embodied Agents with cultural Context, In S Payr \& Trappl (eds.), Agent Culture: Human -Agent Interaction in a Multicultural World, London: Lawrence Erlbaum Associates pp.107-125 (2004)..

[Bull 1987] Bull,P.E.: Posture and Gesture, Pergamon Press, Oxford (1987)

[Cassell et al 2001] J. Cassell, Y. Nakano, T. Bickmore, C. Sidner, C. Rich : Non-verbal Cues for Discourse Structure, The 39th Annual Meeting of the Association for Computational Linguistic (ACL 01), pp 106-115 (2001)

[Dana et al. 2005] Dana R. Carney, Judith A. Hall, and
Lavonia S. LeBeau: Beliefs about the non-verbal expression of social power. Journal of Nonverbal Behavior, Springer Science Business Media, Inc. 29(2), pp.105-123 (2005)

[Dusan 2007] Dusan Jan, David Herrera, Bilyana Martinovski, David Novick, and David Traum : A Computational Model of Culture-Specific Conversational Behavior. In Proceedings of the Intelligent Virtual Agents, Catherine Pelachaud et al. editors, Berlin, Heidelberg, Springer, pp. 45-56, (2007).

[Efron 1972] Efron, D.: Gesture, Race and Culture, Mouton and Co. (1972)

[Gaspy 2008] A. Gaspay, S. Dardan, and L. Legorreta : Software of the Mind - A Review of Applications if Hofstede's Theory to IT Research, Journal of Information Technology Theory and Application (JITTA), pp.1-37 (2008)

[Gallaher 1992] Gallaher, P.E.: Individual Differences in Non-verbal Behavior; Dimension of style, Journal of Personality and Social Psychology 63819, pp.133-145 (1992)

[GeNIe 1998] GeNIe and SMILE, http://genie.sis.pitt.edu/ (1998)

[Hartmann 2005] B. Hartmann, M. Mancini, S. Buisine, C. Pelachaud: Design and evaluation of expressive gesture synthesis for embodied conversational agents, In Proceedings of the fourth international joint conference on Autonomous agents and multi-agent systems, pp. 1095-1096 (2005)

[Hofstede 2001] G. Hofstede: Cultures Consequences Comparing Values, Behaviors, Institutions and Organizations Across Nation, Stage Publications, Thousand Oaks London (2001)

[Isbister 2004] K. Isbister: Building bridges through Unspoken: Embodied Agent Facilitate Intercutural Communication, In S. Payr \& Trappl (eds.), Agent Culture: Human -Agent Interaction in a Multicultural World, London: Lawrence Erlbaum Associates., pp.233-244 (2004).

[Kipp, M. 2001] Kipp, M.: Anvil - A Generic Annotation Tool for Multimodal Dialogue, In Proceedings of the 7th European Conference on Speech Communication and Technology, pp. 1367-1370 (2001)

[Lipi 2009 ] Afia Akhter Lipi , Yukiko Nakano and Mathias Rehm: A Parameter-based Model for Generating Culturally Adaptive Nonverbal Behaviors in Embodied Conversational Agents, In HCII 2009, San Diego, pp. 631-640 (2009).

[O’Neill-Brown 1997] P. O'Neill-Brown: Setting the stage for the culturally adaptive agent, In Proceedings of the 1997 
AAAI Fall Symposium on Socially Intelligent Agents, pp. 93-97 (1997).

[Pelachaud 2005] C. Pelachaud : Multimodal expressive

Embodied conversational agents In Proceedings of ACM Multimedia. pp. 683-689 (2005)

[Robert et al. 1985] Robert M. Krauss et al.: Language and Social Behavior, In D.Gilbert, S. Fiske \& G. Lindsey (Eds.), Handbook of social psychology (4h ed.), Vol. 2. (pp. 41-88). (1985).

[Rehm \& Nakano 2009] Matthias Rehm, Yukiko Nakano, Elisabeth Andrè, Toyoaki Nishida, Nikolaus Bee, Birgit Endrass, Michael Wissner, Afia Akhter Lipi, and Hung-Hsuan Huang: From observation to simulation: generating culture-specific behavior for interactive systems, In AI \& Society, Special Issue on Enculturating Human Computer Interaction, Vol. 24, No. 3, pp. 267-280 (2009)

[Sanchez 2009] J. Sanchez-Burks, C. Bartel, S. Blount: Fluidity and performance in intercultural workplace interactions: The role of behavioral mirroring and social sensitivity, Journal of Applied Psychology, 94(1), pp. 216-223 (2009).

[Samuel et al. 2009] Samuel M. et al.: One for All or One for One, The influence of Cultural Dimensions in Virtual Agent's Berhavior, IVA Sept 2009 Proceedings, Amsterdam, Netherland, pp. 272-28, (2009).

[Samuel et al. 2009a] Samuel Mascarenhas et al.: Using rituals to Express Cultural Differences in Synthetic Charaters, In AAMAS 2009 Proceedings, Budapest, Hungary. Amsterdam, Netherland, pp. 305-312 (2009).

[Spencer-Oatey 1996] H. Spencer-Oatey: Reconsidering power and distance, Journal of Pragmatics , vol. 26 , pp.1-24 (1996)

[Ting-Toomey,S 1999] Ting-Toomey S.: Communicating Across Cultures, The Guilford Press, New York, (1999)

[Triandis \& Harry C. 1989] Triandis \& Harry C. : The self and social behavior in differing cultural contexts, Psychological Review, pp.506-520 (1989).
Author's Profile



Afia Akhter Lipi

A Research Student at Intelligent Interface Lab of Seikei University since April 2009. Before that, she obtained her MSc. In Engineering from Tokyo University of Agriculture and Technology in 2009. Her main research interests include Embodied conversational agent, cultural computing, and enculturating non-verbal communicative behavior.

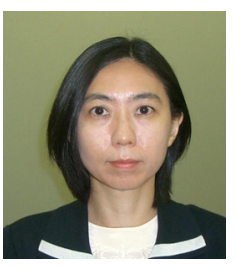

Professor Yukiko Nakano (Member)

An associate professor in the Department of Computer and Information Science at Seikei University, Japan. She received her M.S. in Media Arts and Sciences from Massachusetts Institute of Technology and Ph.D. in Information Science and Technology from the University of Tokyo. Her current research interests are human-computer interaction and conversational agents, as well as studying human's verbal and nonverbal behaviors in discourse and dialogue.

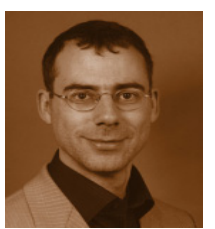

\section{Professor Dr. Matthias Rehm}

An associate professor at CREATE, the Department of Architecture, Design and Media Technology at Aalborg University. He received his doctor degree from Bielefeld University for a thesis on multimodal learning in virtual agents and has since worked in the area of social interactions focusing on embodied agents, cultural aspects of computing and multimodal interaction. $\mathrm{He}$ has been involved in a number of international research projects on a European level and beyond and has over 50 publications in peer-reviewed journals and conferences.

〔担当委員 : 寺田和憲〕

2010 年 02 月 08 日 受理 